\title{
Spatial and Temporal Variation of Annual Precipitation in a River of the Loess Plateau in China
}

\author{
Cui Shen and Huang Qiang \\ State Key Laboratory of Eco-Hydraulic Engineering in Shaanxi, School of Water Resources and Hydropower, \\ Xian University of Technology, Xian 710048, China \\ Correspondence should be addressed to Huang Qiang; wresh@mail.xaut.edu.cn
}

Received 9 October 2013; Accepted 20 December 2013; Published 19 February 2014

Academic Editor: G. H. Huang

Copyright (C) 2014 C. Shen and H. Qiang. This is an open access article distributed under the Creative Commons Attribution License, which permits unrestricted use, distribution, and reproduction in any medium, provided the original work is properly cited.

\begin{abstract}
Empirical orthogonal function (EOF) decomposition and geostatistical (semivariogram) analysis are used to analyze the spatial and temporal patterns of annual precipitation in the Weihe basin based on the data from 1960 to 2011 at 30 national meteorological stations within and surrounding the Weihe basin area of the Loess Plateau in China. Then the Mann-Kendall method is used to discriminate the variation points of precipitation series at each station. The results show that, during the study period, there was an overall reduction in annual precipitation across the basin and there were two spatial patterns: increase in the northwest, decrease in southeast and increase in the west, decrease in east. Variation points in the annual precipitation series at each meteorological station in the basin were detected, and they occur earliest in the southeast and downstream, then progressively later in the northwest and upstream areas. These variations were most frequent during the 1970s and 1980s. The findings have significant implications for the variations research of runoff in the basin and formulate robust strategies to adapt to climate change and mitigate its effects.
\end{abstract}

\section{Introduction}

Climate change is causing increasing concerns globally. Precipitation is a key climatic parameter that strongly affects runoff and diverse hydrological variables. Thus, knowledge of precipitation patterns is essential for characterizing past and present climate changes, predicting future changes, and evaluating their effects. Several studies have shown that annual precipitation in China is declining $[1,2]$, while the frequency of extreme weather events is increasing [3]. The changes in precipitation are closely related to changes in runoff and thus are affecting ecosystems and restricting socioeconomic development [4]. In the Weihe basin, located in the eastern part of northwest China, there are fragile ecosystems and frequent natural disasters. Thus, analysis of the spatial and temporal variation in precipitation in the basin is essential for understanding changes in runoff and the associated socioeconomic and ecological impact in the region and for formulating robust, cost-effective strategies to adapt to and mitigate the effects of climate change.

\section{Study Area}

Weihe River of the Loess Plateau in China originates in the north of Niaoshu mountain in Weiyuan county of Gansu province, emptying into the Yellow River at Tongguan county of Shaanxi province, which has a drainage area of $135000 \mathrm{~km}^{2}$ and flows $818 \mathrm{~km}$ eastwards through 84 counties and three provinces across the guanzhong basin [5]. The Weihe basin spans longitude and latitude ranges of $103.5^{\circ} \sim 110.5^{\circ} \mathrm{E}$ and $5^{\circ} \sim 37.5^{\circ} \mathrm{N}$, respectively, and the two main tributaries are the rivers Jinghe and Beiluohe [6]. The southeast part of the basin is located in the continental monsoon zone, while the northwest part is in the transitional zone between arid and humid regions, controll by West Pacific subtropical high and Mongolia High, the basin is drought in spring, rainy hot in summer but drought frequent, dry cold in autumn and winter [7]. There are major annual variations in precipitation, which is concentrated in July to October, when about $65 \%$ of annual precipitation occurs [8]. The average temperature is $-1^{\circ}$ to $-3^{\circ} \mathrm{C}$ in the coldest month (January) and $23^{\circ} \sim 26^{\circ} \mathrm{C}$ in the warmest month (July) [9]. 


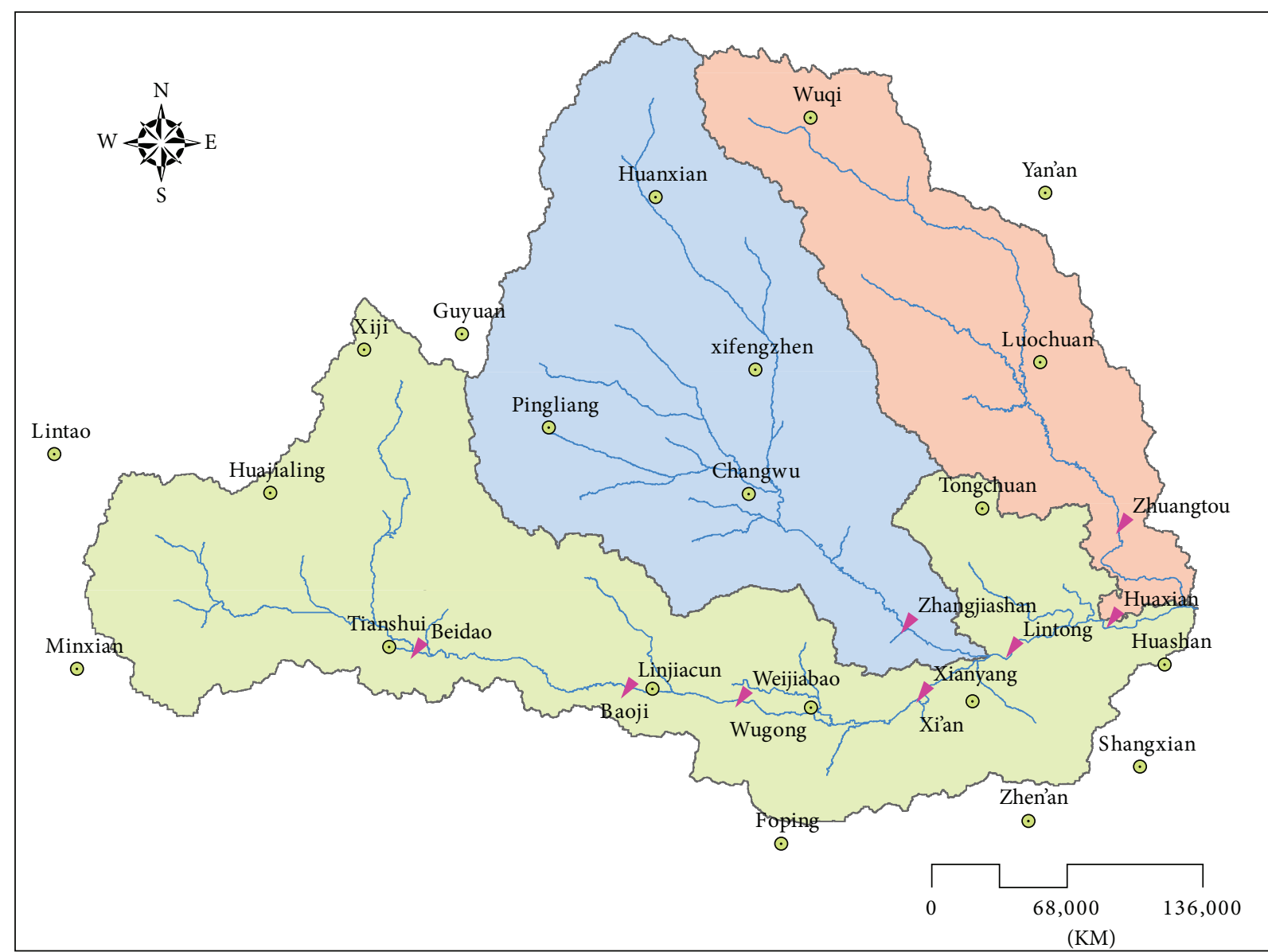

\footnotetext{
- Hydrologic station

$\odot$ Meteorological station

River

Jinghe basin
}

Beiluohe basin

B-H section of Weihe basin

Weihe basin above Beidao station

FIgURE 1: Map of the Weihe basin showing the four subbasins and locations of hydrological and meteorological stations.

Climate changes have had marked effects in the Weihe basin. Thus, we have examined changes in annual precipitation in the basin, from 1960 to 2011, in order to elucidate their spatial and temporal patterns, thereby facilitating attempts to formulate effective mitigation strategies. For the purposes of the study, the Weihe basin is divided into four subbasins with distinct hydrological characteristics and control stations: the basin above Beidao station, Jinghe basin, Beiluohe basin, and the Beidao to Huaxian section of the Weihe mainstream. A map showing the areas covered by these subbasins and locations of hydrological and meteorological stations is presented in Figure 1.

\section{Data Sources and Methodology}

3.1. Data Sources. The annual precipitation data used in this paper are recorded from 1960 to 2011 at 30 National Standard Stations in the Weihe basin and the surrounding area obtained from the China Meteorological Data Sharing Service System (http://cdc.cma.gov.cn/home.do).

3.2. Methodology. First we calculate means in annual precipitation in the Weihe basin by statistical methods and determine trends by regression analysis. Then we use empirical orthogonal function (EOF) decomposition and geostatistical analysis method to analyze spatial and temporal patterns associated with precipitation. Eigenvectors obtained from EOF decomposition are then multiplied by trend vectors in the matrix of the precipitation series to obtain eigenvector fields, thus describing the spatial trends in annual precipitation. Finally, we use the Mann-Kendall (M-K) method to identify variation points in the precipitation series for each station, thereby comprehensively describing the temporal and spatial patterns of annual precipitation in each of the subbasins. 
3.2.1. Regression Analysis. Regression analysis is applied to analyze the correlationship of two variables, which determines relative direction and intensity. In this study, regression analysis is used to get the linear regression of precipitation and time, and the equation is as follows:

$$
P=a T+b
$$

where $P$ is the precipitation, $T$ is the time, and $a$ and $b$ are parameters. If the unit of $T$ is the year, usually $a$ is the changing trend of annual precipitation.

3.2.2. Empirical Orthogonal Function Decomposition. EOF decomposition involves decomposition of a matrix $\mathbf{X}$ of data describing the distribution of a variable in both space and time into a spatial function $\mathbf{V}$ and time function $\mathbf{T}$ as shown in

$$
\begin{gathered}
\mathbf{X}=\mathbf{V T} \\
\mathbf{X}=\left[\begin{array}{ccccc}
x_{11} & \cdots & x_{1 j} & \cdots & x_{1 n} \\
\vdots & & \vdots & & \vdots \\
x_{i 1} & \cdots & x_{i j} & \cdots & x_{i n} \\
\vdots & & \vdots & & \vdots \\
x_{m 1} & \cdots & x_{m j} & \cdots & x_{m n}
\end{array}\right],
\end{gathered}
$$

where $m$ and $n$ are points in space and time, respectively, and $x_{i j}$ is the value of the variable at point $i$ and time $j$ (here, annual precipitation at station $i$ in year $j$ ).

If $\mathbf{V}$ and $\mathbf{T}$ are orthogonal,

$$
\begin{aligned}
& \sum_{i=1}^{m} v_{i k} v_{i l}=1, \quad \text { when } k=l, \\
& \sum_{j=1}^{n} t_{k j} t_{l j}=0, \quad \text { when } k \neq l .
\end{aligned}
$$

If $\mathbf{X}$ is an anomaly matrix (reference), multiplying the equation $\mathbf{X}=\mathbf{V T}$ by $\mathbf{X}^{\mathrm{T}}$ gives

$$
\mathbf{X X}^{\mathrm{T}}=\mathrm{VTX}^{\mathrm{T}}=\mathrm{VTT}^{\mathrm{T}} \mathbf{V}^{\mathrm{T}}=\mathrm{V} \boldsymbol{\Lambda} \mathbf{V}
$$

where $\Lambda$ is a diagonal matrix composed of eigenvalues $\lambda_{i}$ of matrix $\mathbf{X} \mathbf{X}^{\mathrm{T}}$ and

$$
\mathrm{TT}^{\mathrm{T}}=\Lambda
$$

Due to the characteristics of the eigenvectors, $\mathbf{V}^{\mathrm{T}} \mathbf{V}$ is a unit matrix, meeting the requirements of orthogonality. Thus, the spatial function matrix $\mathbf{V}$ can be calculated from eigenvectors of the matrix $\mathbf{X X}^{\mathbf{T}}$.

Here, we multiply the spatial function matrix $\mathbf{V}$ of annual precipitation in the Weihe basin by the trend vector $\mathbf{D}=$ $\{d 1, d 2, \ldots, d m\}$, composed of trends in annual precipitation recorded at each station $\left(\mathbf{V}_{d}=\mathbf{D V}\right)$, thus describing the spatial trends of annual precipitation in the basin.

EOF decomposition was first established in 1902 [10]. It decomposes elements of a set of space-time data into two functions, one dependent only on time and another dependent only on space, to analyze the spatial structure of element fields [11]. Thus, EOF decomposition is commonly used to analyze spatial and temporal variations in meteorological elements. In contrast, principal component analysis (PCA) is mainly used to find a few independent vectors in a dataset to reduce its dimensionality, thereby simplifying data handling and interpretation. However, the operational steps are basically the same, when the original variables are anomaly data or standardized anomaly data [12]. Hence, we can use the PCA module of SPSS (statistical product and service solution) software for EOF decomposition [13].

EOF decomposition and several variants thereof have been widely applied for analyzing spatial changes in meteorological elements. Notably, EOF decomposition has been used to analyze drought occurrence in both time and space in Korea [14]. It has also been applied to establish contributions of annual evaporation, annual precipitation, and both warm- and cold-season precipitation to the annual runoff of rivers in an arid zone to obtain quantitative estimates of the effects of climatic factors on reconstructions of annual runoff series in an ungauged area [15]. A data-interpolating empirical orthogonal function (DINEOF) has been used to analyze distributions of sea surface temperatures in a study demonstrating that DINEOF decomposition can be highly effective, even when very high proportions of data are missing [16]. In addition, rotated empirical orthogonal function (REOF) decomposition has been applied to analyze spacetime patterns of groundwater fluctuations in the Choshui River alluvial fan, Taiwan, based on monthly observations of piezometric heads from 66 wells during the period 1997-2002 [17].

3.2.3. Mann-Kendall Variation Analysis. The Mann-Kendall test has been widely used for identifying trends in timeseries data because it is nonparametric and thus suitable for handling data that are not normally distributed, and it is not sensitive to interference from a few outliers. The MannKendall test can also be used for variation diagnosis, and the calculation method is as follows.

For a time series $X=\left\{x_{1}, x_{2}, \ldots, x_{n}\right\}$, the Mann-Kendall test statistic $D_{\tau}$ is given by the following model:

$$
D_{\tau}=\sum_{i=1}^{\tau} R_{i} \quad(\tau=2,3, \ldots, i),
$$

where

$$
R_{i}=\left\{\begin{array}{ll}
+1, & x_{i}>x_{j} \\
0, & x_{i} \leq x_{j}
\end{array} \quad(j=1,2, \ldots, i)\right.
$$

The sequential statistic $U_{\tau}$ (in which $U_{1}=0$ ) is calculated by is

$$
\mathrm{UF}_{\tau}=\frac{\left|D_{\tau}-E\left(D_{\tau}\right)\right|}{\sqrt{V\left(D_{\tau}\right)}}
$$




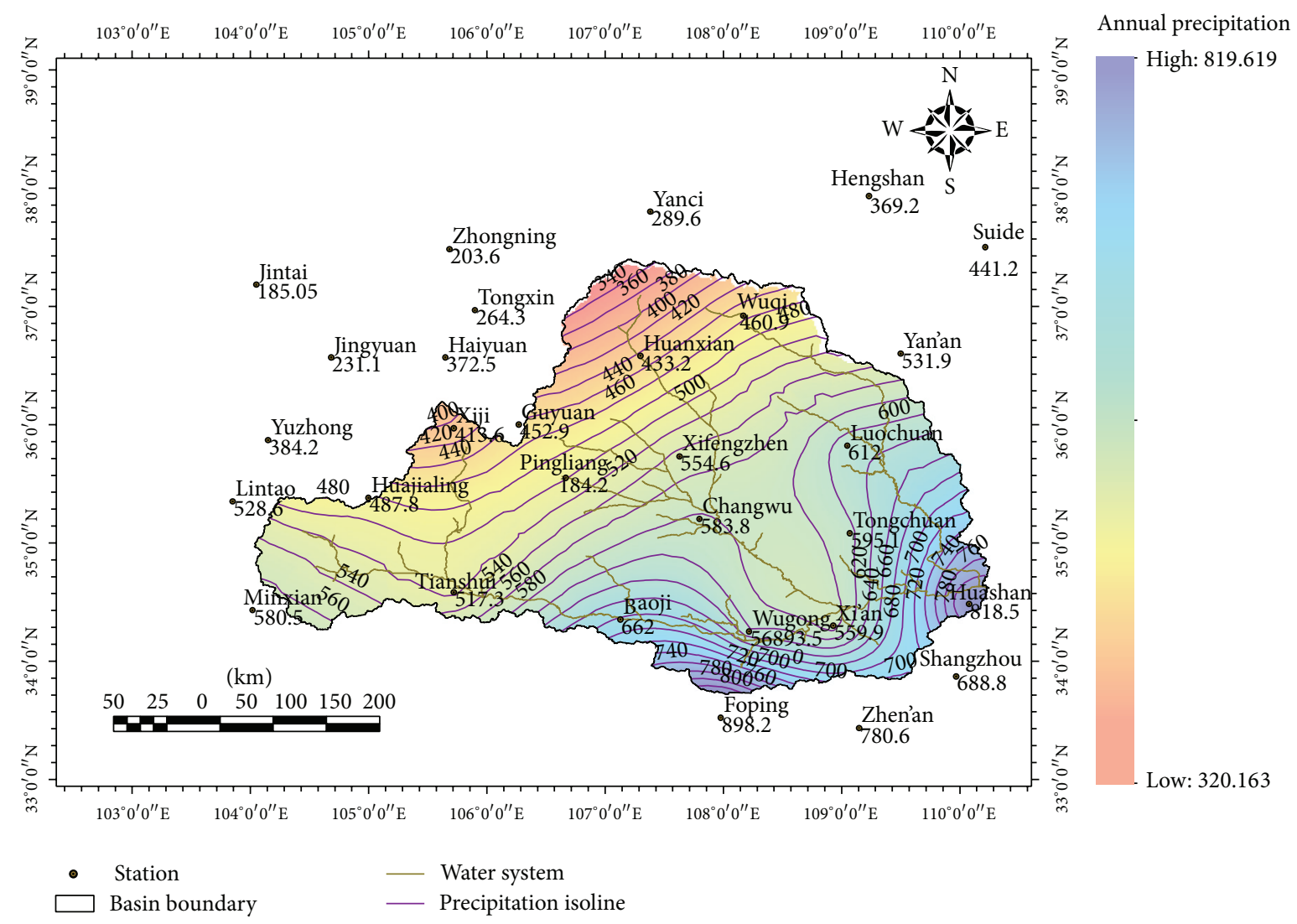

FIGURE 2: Isohyets showing mean annual precipitation in the Weihe basin.

where $E\left(D_{\tau}\right)$ and $V\left(D_{\tau}\right)$ are the mean and variance of the series, given, respectively, by

$$
\begin{gathered}
E\left(D_{\tau}\right)=\frac{\tau(\tau-1)}{4}, \\
V\left(D_{\tau}\right)=\frac{\tau(\tau-1)(2 \tau+5)}{72} .
\end{gathered}
$$

Then repeat the calculation with the inversion series $X^{\prime}=$ $\left\{x_{n}, x_{n-1}, \ldots, x_{1}\right\}$, and let $\mathrm{UB}_{\tau}=-\mathrm{UF}_{\tau},(\tau=n, n-1, \ldots, 1)$. Define the significant level $\alpha$, and find out the critical value $\pm U_{(1-\alpha) / 2}$. If the curves of $\mathrm{UF}_{\tau}$ and $\mathrm{UB}_{\tau}$ intersect and the intersections are between the critical line (in this study, the significant level $\alpha$ is 0.95 , and the critical line is $\pm U_{0.05 / 2}=$ \pm 1.96 ), the time of curve intersections is the starting time of the variation.

Originally published in 1945 [18], it was initially only used to detect trends in sequences. However, subsequent modifications have enabled its use for detecting variation points in various trends [19], and it has been applied in reversed sequence to detect variation points in trends in climate data time series [20]. Since then the method has been widely used to diagnose variation points in hydrological and meteorological data sequences [21, 22]. Notably, the M$\mathrm{K}$ method has been used to determine whether there were positive or negative trends in seven meteorological variables (and if so their significance) recorded at 12 weather stations in
Serbia during 1980-2010 [23]. A modified form of the method has also been used to test scaling effects [24], and four variants have been applied to determine trends in selected streamflow statistics from Indiana [25]. In addition, a procedure for calculating exact distributions of the M-K trend test statistic for persistent data with an arbitrary correlation structure has been presented [26], and the test has been used to detect directions and magnitudes of changes in monotonic trends in annual and seasonal precipitation over time in annual precipitation in Madhya Pradesh, India [27]. Here, we applied the $\mathrm{M}-\mathrm{K}$ test to detect trends variation points in the time series of the data obtained from the 30 stations in the Weihe basin (Figure 1).

\section{Results}

4.1. Spatial Patterns of Annual Precipitation in the Weihe Basin. Means and trends in annual precipitation in the Weihe basin from 1960 to 2011 are shown in Figures 2 and 3. The mean annual precipitation at each station changed greatly. Spatially, it declined from the southeast to northwest. Mean annual precipitation in the basin amounted to $580 \mathrm{~mm}$, with a maximum exceeding $800 \mathrm{~mm}$ at Huashan and Zhen'an area and a minimum of $340 \mathrm{~mm}$ in the northwest. The annual precipitation trend at each station was negative, except at Xian where it increased by $0.123 \mathrm{~mm} / \mathrm{a}$. The mean trend 


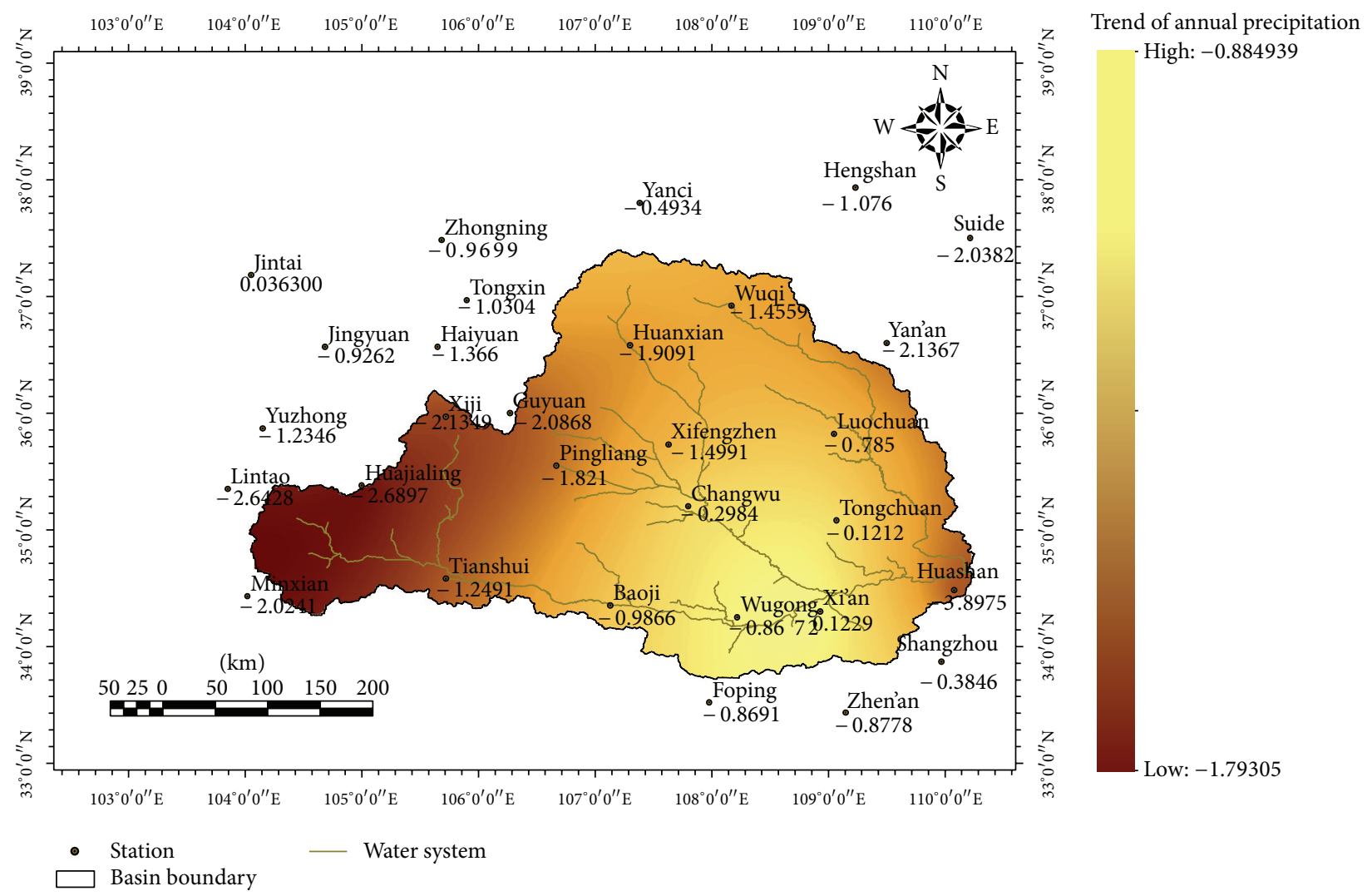

FIgURE 3: Annual precipitation trends in the Weihe basin.

TABLE 1: Eigenvalues and their contributions to the variance of annual precipitation in the Weihe basin obtained from EOF decomposition.

\begin{tabular}{|c|c|c|c|c|c|c|}
\hline \multirow[b]{2}{*}{ Component } & \multicolumn{3}{|c|}{ Initial eigenvalues } & \multicolumn{3}{|c|}{ Extraction sums of squared loadings } \\
\hline & $\begin{array}{c}\text { Eigenvalues } \\
\lambda_{i}\end{array}$ & $\begin{array}{l}\text { Proportion of } \\
\text { variation (\%) }\end{array}$ & $\begin{array}{l}\text { Cumulative } \\
\text { proportion of } \\
\text { variation (\%) }\end{array}$ & $\begin{array}{c}\text { Eigenvalues } \\
\lambda_{i}\end{array}$ & $\begin{array}{l}\text { Proportion of } \\
\text { variation (\%) }\end{array}$ & $\begin{array}{l}\text { Cumulative } \\
\text { proportion of } \\
\text { variation (\%) }\end{array}$ \\
\hline 1 & 13.648 & 45.494 & 45.494 & 13.648 & 45.494 & 45.494 \\
\hline 2 & 5.363 & 17.875 & 63.369 & 5.363 & 17.875 & 63.369 \\
\hline 3 & 1.997 & 6.658 & 70.027 & 1.997 & 6.658 & 70.027 \\
\hline 4 & 1.404 & 4.681 & 74.708 & & & \\
\hline 5 & 1.196 & 3.985 & 78.693 & & & \\
\hline 6 & 0.912 & 3.039 & 81.732 & & & \\
\hline 7 & 0.685 & 2.285 & 84.017 & & & \\
\hline 8 & 0.634 & 2.113 & 86.130 & & & \\
\hline 9 & 0.506 & 1.686 & 87.816 & & & \\
\hline 10 & 0.422 & 1.408 & 89.224 & & & \\
\hline
\end{tabular}

Extraction method: principal component analysis.

across the basin was $-1.662 \mathrm{~mm} / \mathrm{a}$, clearly showing that annual precipitation declined and that this trend was most pronounced in upstream areas.

4.2. EOF Decomposition of Annual Precipitation in the Weihe Basin. The precipitation data analyzed herein originated from the Weihe basin and the surrounding 30 national standard stations during the period 1960-2011. From this data, we derived the normalized anomaly matrix $\mathbf{X}$ for annual precipitation. Empirical orthogonal function (run in SPSS) was used to calculate the eigenvalues of the covariance matrix of $\mathbf{X}$ and the amount of variation that each principal component explained, as shown in Table 1.

Eigenvalues for the covariance matrix of the Weihe basin annual precipitation matrix and their contributions to variance (specific and cumulative), obtained by empirical 
orthogonal function (using SPSS software), are shown in Table 1 . The precipitation field rapidly converged; the first principal component (PC) accounted for almost half (45.5\%) of the variation in annual precipitation, and the first three components (all of which had eigenvalues exceeding 1) for $70.0 \%$ of the variation. Thus, the first three PCs and eigenvectors describe the spatial distribution of annual precipitation in the Weihe basin quite well.

Eigenvectors of the covariance matrix cannot be directly obtained from the SPSS output but can be obtained by dividing the $i$ vectors of the matrix by the square roots of the corresponding eigenvalues. The vector corresponding to the largest eigenvalue is eigenvector 1 , with progressively small eigenvalues associated with subsequent eigenvectors $(2,3$, 4 , etc.). The first three eigenvectors obtained from the EOF decomposition of the annual precipitation in the Weihe basin dataset are shown in Table 2.

The first three eigenvectors obtained from the EOF analysis provide an approximate description of the precipitation values. If their values are consistently positive or negative, there is a consistent precipitation trend, and the area with the largest absolute value is the center of the variable field. In contrast, if the eigenvector values fluctuate between positive and negative, the trend is nonuniform.

We used the Geostatistical Analyst module of ArcGIS to undertake a semivariogram analysis of the first three eigenvectors and thus, to obtain the spatial variability parameters shown in Table 3 . We then used Kriging interpolation to draw a map of each eigenvector field.

As can be seen from Table 3, the azimuth angles of eigenvectors 1,2 , and 3 are $4.7^{\circ}, 65.5^{\circ}$, and $309.6^{\circ}$, approximately south to north, east-northeast to west-southwest, and northwest to southeast orientations, respectively. All the eigenvectors have a small Nugget value, indicating that the precipitation measurement error is small. Indeed, the Nugget of eigenvector 2 is zero, indicating that the measurement error for precipitation in this eigenvector field can be ignored. The partial sill of eigenvector 1 is significantly lower than that of the other eigenvectors, indicating that it reflects smaller-scale variations. The Weihe basin spans about $7^{\circ}$ longitude and $4^{\circ}$ latitude. Thus, since the major ranges in the eigenvectors are $6.29^{\circ}$ latitude and longitude, the variability of precipitation changes with distance across the basin.

4.3. Variation Diagnosis of Annual Rainfall in the Weihe Basin. The Weihe basin is divided into four subbasins, with differing hydrological characteristics, and controlled by different hydrological stations. The areas covered by the subbasins and locations of hydrological and meteorological stations are shown in Figure 1. The M-K method was used to discriminate variation points in the trends in the annual precipitation series recorded at each station during 1960-2011, and the results are shown in Table 4.

\section{Analysis and Discussion of Results}

5.1. Analysis of Spatial Variation of Annual Precipitation in the Weihe Basin. As shown in Table 2, all components of
TABLE 2: Eigenvectors obtained by EOF decomposition of the annual precipitation in the Weihe basin dataset.

\begin{tabular}{|c|c|c|c|}
\hline & \multicolumn{3}{|c|}{ Eigenvectors } \\
\hline & $\begin{array}{c}\text { Eigenvector } 1 \\
V_{1} \\
\end{array}$ & $\begin{array}{c}\text { Eigenvector } 2 \\
V_{2} \\
\end{array}$ & $\begin{array}{c}\text { Eigenvector } 3 \\
V_{3} \\
\end{array}$ \\
\hline Lintao & 0.190 & -0.137 & -0.291 \\
\hline Huajialing & 0.190 & -0.043 & -0.383 \\
\hline Wuqi & 0.196 & -0.157 & 0.112 \\
\hline Guyuan & 0.224 & -0.082 & -0.086 \\
\hline Huanxia & 0.210 & -0.140 & 0.086 \\
\hline Yan'an & 0.208 & 0.011 & 0.251 \\
\hline Xiji & 0.192 & -0.131 & -0.308 \\
\hline Pingliang & -0.070 & 0.045 & -0.019 \\
\hline Xifengzhen & 0.222 & 0.104 & 0.067 \\
\hline Changwu & 0.204 & 0.201 & 0.058 \\
\hline Luochuan & 0.200 & 0.139 & 0.179 \\
\hline Tongchua & 0.154 & 0.248 & 0.168 \\
\hline Minxian & 0.202 & 0.001 & -0.271 \\
\hline Tianshui & 0.204 & 0.057 & -0.241 \\
\hline Baoji & 0.167 & 0.287 & -0.021 \\
\hline Wugong & 0.180 & 0.273 & -0.010 \\
\hline Xi'an & 0.158 & 0.277 & 0.051 \\
\hline Huashan & 0.163 & 0.215 & -0.100 \\
\hline Foping & 0.177 & 0.218 & 0.009 \\
\hline Zhen'an & 0.157 & 0.245 & 0.042 \\
\hline Shangzhou & 0.167 & 0.223 & -0.021 \\
\hline Jingtai & 0.119 & -0.198 & 0.272 \\
\hline Jingyuan & 0.167 & -0.250 & -0.084 \\
\hline Yuzhong & 0.178 & -0.156 & -0.281 \\
\hline Zhongning & 0.182 & -0.206 & 0.127 \\
\hline Yanci & 0.170 & -0.200 & 0.250 \\
\hline Hengshan & 0.183 & -0.120 & 0.240 \\
\hline Suide & 0.175 & -0.108 & 0.260 \\
\hline Haiyuan & 0.199 & -0.231 & 0.004 \\
\hline Tongxin & 0.192 & -0.221 & 0.072 \\
\hline
\end{tabular}

TABLE 3: Spatial variability parameters of eigenvectors of annual precipitation in the Weihe basin.

\begin{tabular}{lccc}
\hline & \multicolumn{3}{c}{ Eigenvectors } \\
& $\begin{array}{c}\text { Eigenvector 1 } \\
V_{1}\end{array}$ & $\begin{array}{c}\text { Eigenvector 2 } \\
V_{2}\end{array}$ & $\begin{array}{c}\text { Eigenvector 3 } \\
V_{3}\end{array}$ \\
\hline Azimuth angle $\left(^{\circ}\right)$ & 4.7 & 65.5 & 309.6 \\
$\begin{array}{l}\text { Nugget }\left(C_{0}\right) \\
\text { Partial sill }(C)\end{array}$ & 0.0012685 & 0 & 0.0013054 \\
$\begin{array}{l}\text { Major range } \\
\text { ( latitude and }\end{array}$ & 0.0014968 & 0.41084 & 0.044187 \\
longitude) & 6.28911 & 6.28911 & 6.28911 \\
\hline
\end{tabular}

eigenvector 1 are positive, except the data from Pingliang station, indicating that precipitation in the Weihe basin had high spatial consistency during the study period. The downward 
TABLE 4: Variation points in annual precipitation trends in the Weihe basin.

\begin{tabular}{|c|c|c|c|c|c|c|}
\hline \multirow{2}{*}{ Subbasins } & \multirow{2}{*}{$\begin{array}{l}\text { Meteorological } \\
\text { stations }\end{array}$} & \multicolumn{5}{|c|}{ Variation points } \\
\hline & & 1960-1969 & 1970-1979 & 1980-1989 & 1990-1999 & 2000-2011 \\
\hline \multirow{5}{*}{$\begin{array}{l}\text { Weihe basin above } \\
\text { Beidao station }\end{array}$} & Tianshui & & 1971 & 1983,1985 & & 2002 \\
\hline & Minxian & & & 1986,1988 & & 2006 \\
\hline & Huajialing & & & 1986 & & \\
\hline & Lintao & & & 1986, 1987 & & $2003,2006,2008$ \\
\hline & Xiji & & & & & 2005 \\
\hline \multirow{5}{*}{ Jinghe basin } & Huanxian & & 1970 & & & 2002 \\
\hline & Guyuan & & 1972 & 1986 & 1996 & \\
\hline & Pingliang & & 1971,1977 & $1980-1985^{*}$ & 1990 & \\
\hline & Xifengzhen & & 1972,1979 & & & \\
\hline & Changwu & & 1978,1979 & 1983,1985 & & \\
\hline \multirow{3}{*}{ Beiluohe basin } & Wuqi & & 1971-1974* & $1981,1983,1$ & $1995^{*}, 1998$ & $2000,2003,2007$ \\
\hline & Yan'an & & $\begin{array}{r}1972-1975^{*} \\
1978,1979\end{array}$ & 1982 & & \\
\hline & Luochuan & & 1970,1976 & & & \\
\hline \multirow{8}{*}{$\begin{array}{l}\text { Beidao to Huaxian } \\
\text { section of Weihe } \\
\text { mainstream }\end{array}$} & Baoji & 1969 & $\begin{array}{l}1971,1974 \\
1976,1978\end{array}$ & 1980,1982 & & \\
\hline & Wugong & $\begin{array}{c}1961, \\
1964-1970^{*}\end{array}$ & & & & \\
\hline & Xi'an & 1962,1965 & & & & \\
\hline & Tongchuan & & 1976 & 1983,1985 & & \\
\hline & Zhen'an & & 1972,1975 & & & \\
\hline & Foping & 1966, 1968 & $\begin{array}{c}1973,1977 \\
1979\end{array}$ & 1986,1988 & & \\
\hline & Shangxian & 1960,1963 & 1971, 1975 & 1984 & & \\
\hline & Huanshan & & & 1986 & & \\
\hline
\end{tabular}

Extraction method: Mann-Kendall method. ${ }^{*}$ indicates that variation occurred frequently during the indicated period.

trend of annual precipitation shows that annual precipitation in the basin declined in the region, and this consistent trend accounts for $45.5 \%$ of the variance. The basin covers parts of the continental monsoon zone and transitional zone between arid and humid regions of northwest China. The overall consistency and decline represented by eigenvector 1 are the main spatial features of precipitation patterns in the Weihe basin during the study period.

The eigenvector 2 values obtained from EOF decomposition of the annual precipitation data are shown in Figure 4. The values can be divided by a line passing roughly from Yan'an through Pingliang to Tianshui, into positive and negative anomaly areas covering the southeastern parts of the Weihe basin (with the most-positive anomaly center in Baoji) and northwestern parts (with the most-negative anomaly center in Wu Qi), respectively. These results confirm that the annual precipitation in the basin has a clear northwestsoutheast pattern.

Combining the eigenvalues with the trends in annual precipitation recorded at each of the stations gives the eigenvector 2 trend values (Figure 5), which show that precipitation declined in the southeast and increased in the northwest. The decline was most pronounced at the downstream station Huashan.
The eigenvector 3 values have a clear eastwest pattern (Figure 6), with a negative anomaly area covering upstream parts of the basin and a positive anomaly center located in the Luochuan region, north of Shaanxi. These findings show that, in addition to the consistent overall pattern and northwestsoutheast precipitation patterns, there is a clear eastwest pattern. In combination with the precipitation trends at the 30 stations, the results clearly show that annual precipitation declined in northern Shaanxi and increased in the upstream areas (Figure 7).

To summarize, there were three spatial patterns of annual precipitation in the Weihe basin during the study period: (1) consistent overall decline, (2) declined in the southeast and increased in the northwest, (3) declined in northern Shaanxi and increased in the upstream areas.

5.2. Analysis of Annual Precipitation Variation in the Weihe Basin. The results summarized in Table 4 show that variation points occurred in trends of the annual precipitation sequence recorded at every meteorological station in the Weihe basin, but their timings differed in the following manner.

(1) The timing of variation points has clear spatial characteristics, with gradual progressions from southeast 


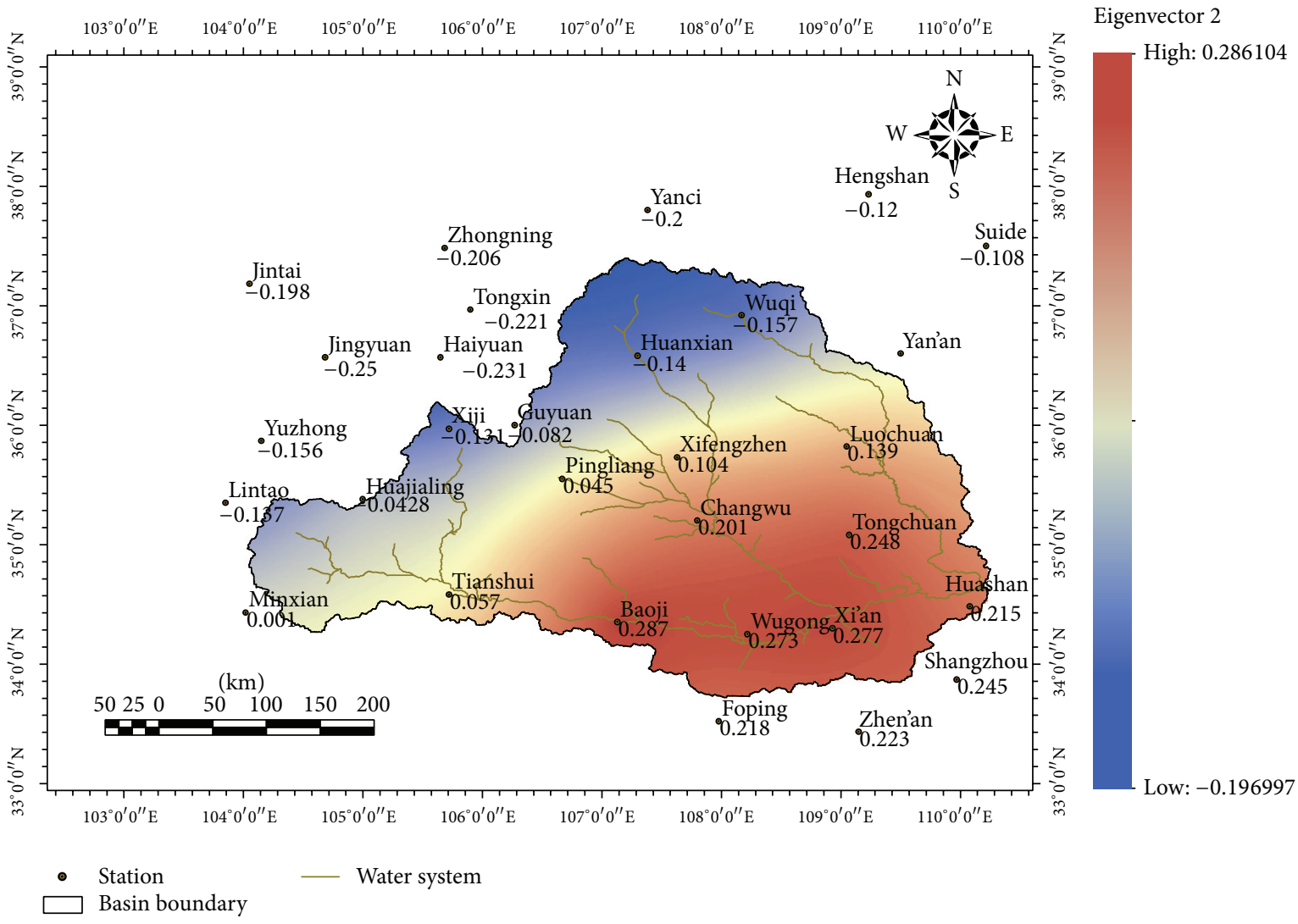

FIGURE 4: The eigenvector 2 values for annual precipitation in the Weihe basin.

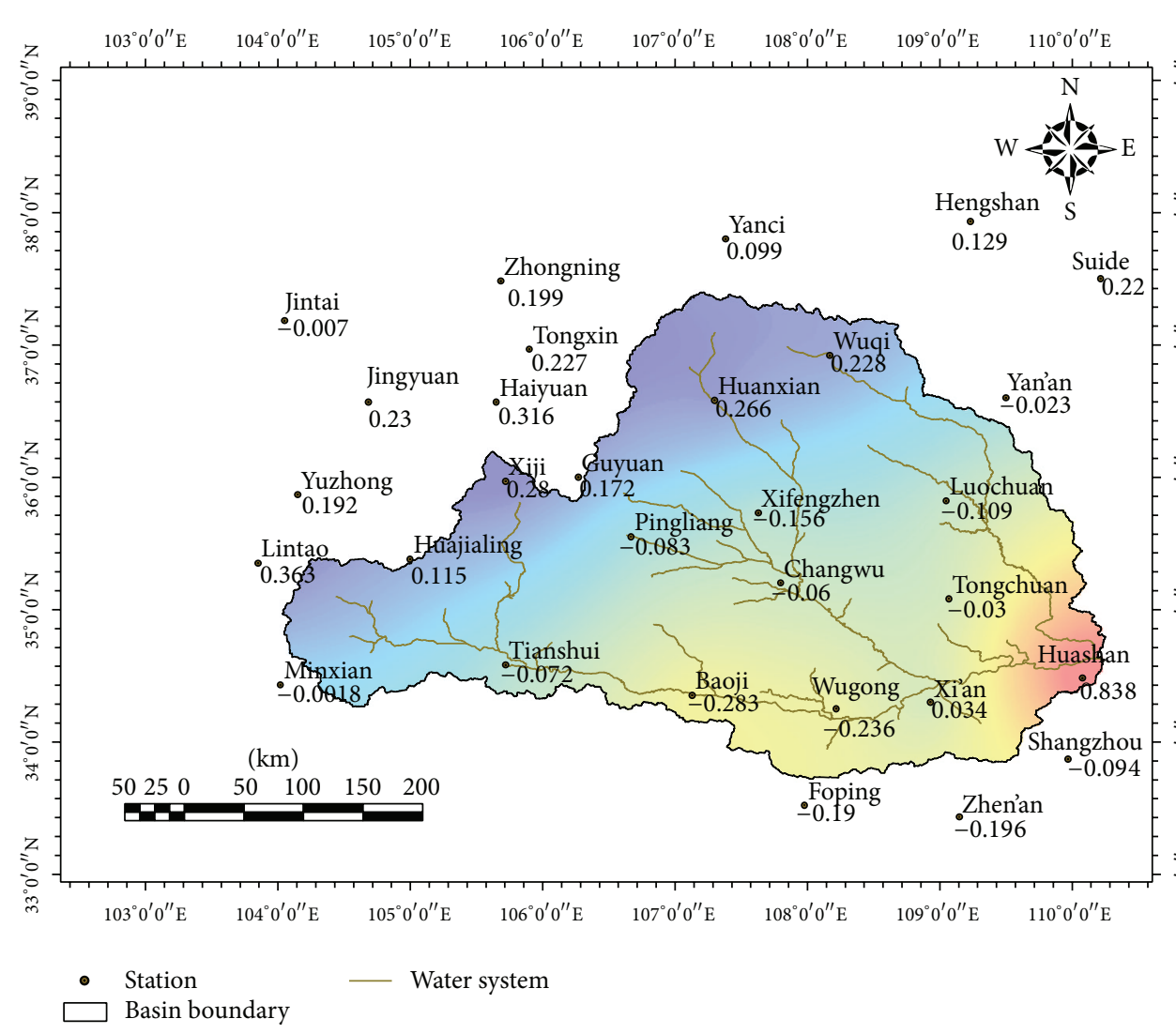

Trend of eigenvector 2 value

FIGURE 5: The eigenvector 2 trend field for annual precipitation in the Weihe basin. 


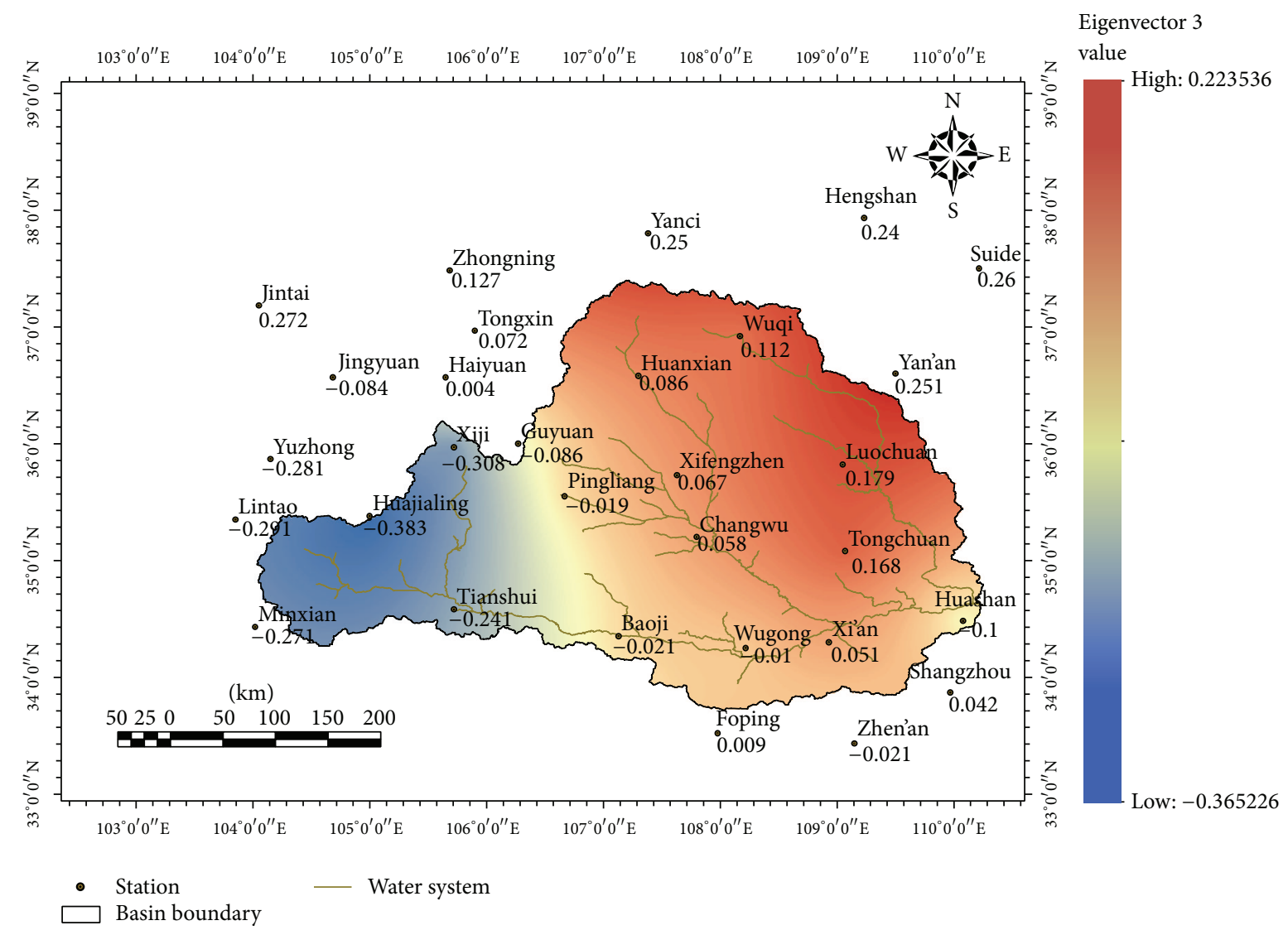

FIGURE 6: The eigenvector 3 values for annual precipitation in the Weihe basin.

to northwest and downstream to upstream. The first variation points occurred in the early 1960s at the Shangxian, Wugong, and Xi'an stations in the Beidao to Huaxian section of the Weihe mainstream, and later in the late 1960s and early 1970s, other stations variation occurred in this section. In the Jinghe and Beiluohe basins the first variation occurred in the early 1970s. In the Weihe basin above Beidao stationand variation occurred most recently, in the mid- and late 1980s, except at Tianshui station (1971).

(2) Variation points in the trends of annual precipitation in the basin above Beidao station were concentrated in the 1980s, while they covered longer periods of the 1970s and 1980s in other subbasins. These results indicate that precipitation variation points occurred frequently during the 1970s to 1980s in each subbasin.

(3) After the 1990s, the frequency and scope of precipitation variation declined. No variation points in the 1990s were detected except at Guyuan, Pingliang, and Wuqi stations. After the 1990s, there were no variation points in the annual precipitation sequences recorded in the Beidao to Huaxian section of the Weihe mainstream, Jinghe basin, or Beiluohe basin. These results show that, after an active period of precipitation variation in 1970s and 1980s, the annual precipitation sequence in the Weihe basin was relatively stable. Thus, during the study period there were shifts in precipitation from one stable state to another after disturbance.

(4) From 2000 to 2011, further changes in annual precipitation occurred in the basin above the Beidao station and at the most northern stations of the basin (Huanxian and Wuqi). These variations were clearly regional, concentrated in the northwest of the Weihe River basin and the source areas of the rivers Jinghe and Beiluohe. Due to the limited length of the time series, it is not possible to distinguish whether these variations were due to small-scale regional variations, or represent initial stages of wide-ranging variation across the whole basin, or were the result of lingering temporal and spatial effects of the basinwide variation that occurred in the 1970s and 1980s.

(5) The variation in annual precipitation in the Weihe basin propagated from the southeast to the northwest. This is consistent with the orientation of the eigenvector 2 field of annual precipitation obtained from EOF decomposition and the spatial pattern of mean annual precipitation in the basin. The factors causing these patterns are not clear from the data presented here but will be addressed in future studies. 


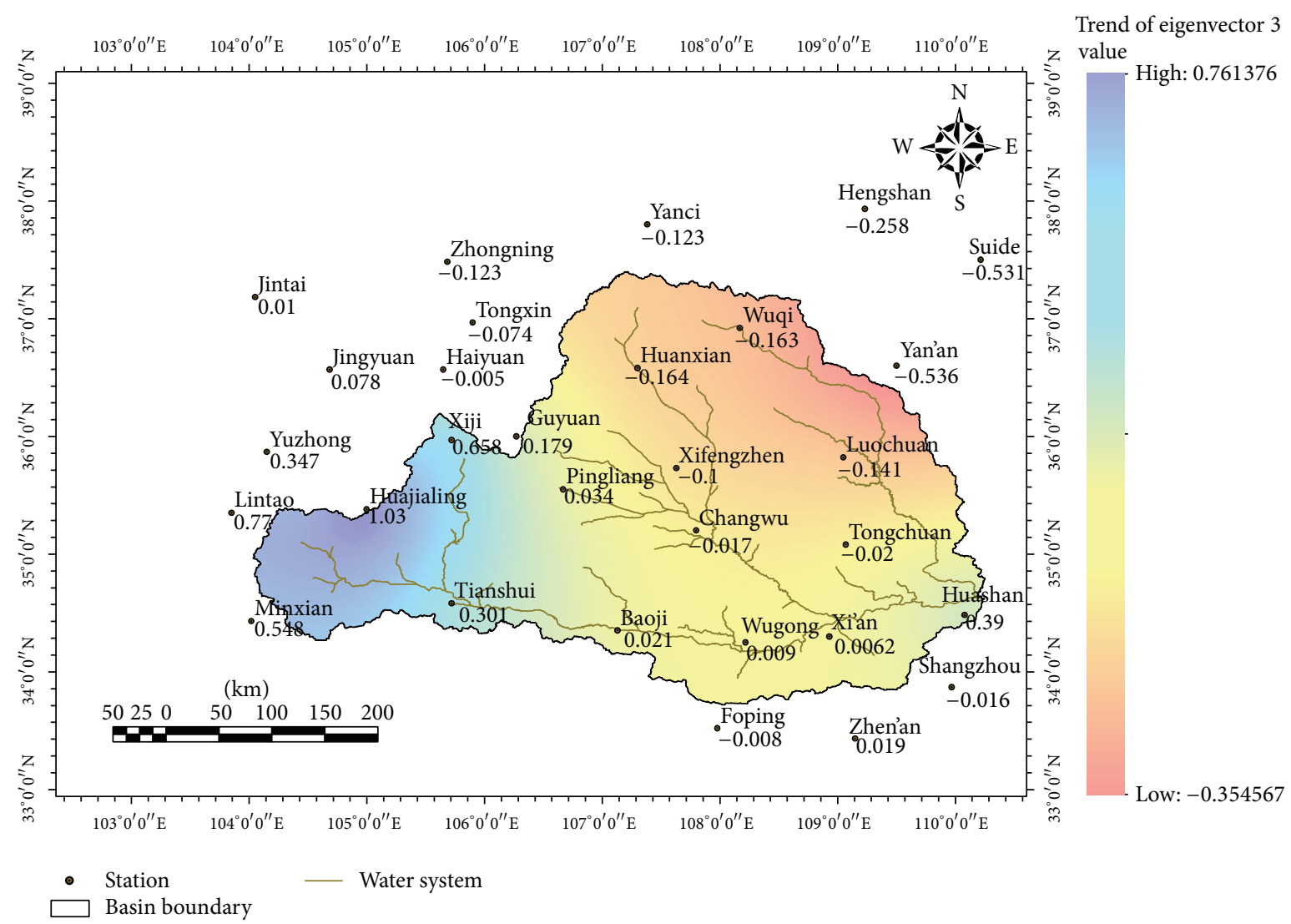

FIGURE 7: The eigenvector 3 trend field for annual precipitation in the Weihe basin.

\section{Conclusions}

We have analyzed spatial and temporal patterns of annual precipitation in the Weihe basin using data recorded from 1960 to 2011 at 30 National Standard Stations in the basin and surrounding area, by applying empirical orthogonal function decomposition in combination with geostatistical (semivariogram) analysis, then using the Mann-Kendall method to discriminate variation points in the precipitation series recorded at each station.

(1) The main spatial patterns of annual precipitation in the Weihe Basin during the study period were a consistent overall decline, which was strongest in the northwest and progressively weaker from northwest to southwest and from west to east. The consistent overall decline accounted for $45.5 \%$ of the total variation.

(2) Variation points were detected in the annual precipitation sequences recorded at all the meteorological stations in the basin, but their timing had clear spatial patterns, starting gradually later from the southeast to the northwest and downstream to upstream. In the 1970s and 1980s they occurred frequently in each subbasin.
(3) After the 1990 s, following the active period of precipitation variation in the 1970s and 1980s, the frequency and scope of precipitation variations declined. Thus, during the study period there were shifts in precipitation from one stable state to another after disturbance.

\section{Conflict of Interests}

The authors declare that there is no conflict of interests regarding the publication of this paper.

\section{Acknowledgments}

This work was financially supported by the Natural Science Foundation of China (Grant nos. 51190093, 51179148, and 51179149), the National Key Basic Research 973 of China (Grant no. 2012CB417003), and the MWR Welfare Sector Funds (Grant nos. 201101043, 201101049). Constructive comments from reviewers of a previous version of the paper are gratefully acknowledged.

\section{References}

[1] H. Zhang, Y. Chen, G. Ren et al., "The characteristics of precipitation variation of Weihe River Basin in Shaanxi Province 
during recent 50 years," Agricultural Research in the Arid Areas, vol. 26, no. 04, pp. 236-241, 2008.

[2] K. Che and J. Jian, "A study of climate variability in Zedang during 1960-1999," Meteorological Monthly, vol. 26, no. 1, pp. 54-56, 2000.

[3] Y. Ding, G. Ren, G. Shi et al., "National assessment report of climate change (I): climate change in China and its future trend," Advances in Climate Change Research, vol. 2, no. 1, pp. 3-8, 2006.

[4] Y. He, F. Wang, X. Mu et al., "Temporal and spatial characteristics of temperature and precipitation in Weihe River basin," Bulletin of Soil and Water Conservation, vol. 32, no. 4, pp. 102105, 2012.

[5] Y.-X. Zhang, F. Wang, and X.-M. Mu, "Research of quantitative relations between Geographical environment factor and water and sediment in the Weihe River basin," Journal of Northwest A \& F University, (Natural Science Edition), vol. 37, no. 1, pp. 61-65, 2009.

[6] C. Jiang, F. Wang, and X. Mu, "Effect of climate change on net primary productivity (NPP) of natural vegetation in Wei river basin (II). NPP of natural vegetation in Wei river basin," Journal of Arid Land Resources and Environment, vol. 27, no. 5, pp. 53-57, 2013.

[7] Y. Zhang, "Hydrologic feature analysis for Weihe basin in Shaanxi province," Northwest Water Resources \& Water Engineering, no. 2, pp. 62-64, 2002.

[8] G. Wang and Y. Wang, "Analysis on causes of runoff and sediment variation in Weihe basin based on hydrological model," Journal of Soil Water Conservation, no. 4, pp. 22-25, 2000.

[9] W. He and Z. Xu, "Spatial and temporal characteristics of the long-term trend for temperature and pan evaporation in the Wei River Basin," Journal of Beijing Normal University (Natural Science), vol. 42, no. 1, pp. 102-106, 2006.

[10] K. Pearson, "On lines and planes of closest fit to system of points in space," Philosophical Magazine, vol. 6, no. 2, pp. 559-572, 1902.

[11] D.-X. Cui and W.-Y. Liu, "Application of empirical orthogonal function resolution to analysis of crustal vertical deformation field," Earthquake, vol. 20, no. 3, pp. 82-86, 2000.

[12] T. Liu and H. Zhang, "Compared with principal component analysis and empirical orthogonal function decomposition," Statistics and Decision, vol. 340, no. 16, pp. 159-162, 2011.

[13] H. Lin and W. Zhang, "Similarities and differences of principal component analysis and factor analysis and SPSS software," Statistics Research, no. 3, pp. 65-69, 2005.

[14] D. H. Kim, C. Yoo, and T.-W. Kim, "Application of spatial EOF and multivariate time series model for evaluating agricultural drought vulnerability in Korea," Advances in Water Resources, vol. 34, no. 3, pp. 340-350, 2011.

[15] N. S. Loboda, A. V. Glushkov, and V. N. Khokhlov, "Using meteorological data for reconstruction of annual runoff series over an ungauged area: empirical orthogonal function approach to Moldova-Southwest Ukraine region," Atmospheric Research, vol. 77, no. 1-4, pp. 100-113, 2005.

[16] D. Sirjacobs, A. Alvera-Azcárate, A. Barth et al., "Cloud filling of ocean colour and sea surface temperature remote sensing products over the Southern North Sea by the Data Interpolating Empirical Orthogonal Functions methodology," Journal of Sea Research, vol. 65, no. 1, pp. 114-130, 2011.

[17] H.-L. Yu and H.-J. Chu, "Understanding space-time patterns of groundwater system by empirical orthogonal functions: a case study in the Choshui River alluvial fan, Taiwan," Journal of Hydrology, vol. 381, no. 3-4, pp. 239-247, 2010.

[18] H. B. Mann, "Nonparametric tests against trend," Econometrica, vol. 13, pp. 245-259, 1945.

[19] R. Snyers, "Sur La Determination de la stabilite des series climatologiques," in Proceedings of the UNESCO-WMO Symposium of Changes of Climate, vol. 20 of Uneseo Arid Zone Research Series, pp. 37-44, Unesco, Paris, France, 1963.

[20] C. Goossens and A. Berger, "Annual and seasonal climatic variations over the northern hemisphere and Europe during the last century," Annales Geophysicae B, vol. 4, no. 4, pp. 385-400, 1986.

[21] C. Fu and Q. Wang, "The definition and detection of the abrupt climatic change," Chinese Journal of Atmospheric Sciences, vol. 16, no. 4, pp. 482-493, 1992.

[22] P. Xie, G. Chen, D. Li et al., "Hydrological variation integrated diagnosis method and application research," Hydroelectric Energy, vol. 23, no. 2, pp. 11-14, 2005.

[23] M. Gocic and S. Trajkovic, "Analysis of changes in meteorological variables using Mann-Kendall and Sen's slope estimator statistical tests in Serbia," Global and Planetary Change, vol. 100, pp. 172-182, 2013.

[24] K. H. Hamed, "Trend detection in hydrologic data: the MannKendall trend test under the scaling hypothesis," Journal of Hydrology, vol. 349, no. 3-4, pp. 350-363, 2008.

[25] S. Kumar, V. Merwade, J. Kam, and K. Thurner, "Streamflow trends in Indiana: effects of long term persistence, precipitation and subsurface drains," Journal of Hydrology, vol. 374, no. 1-2, pp. 171-183, 2009.

[26] K. H. Hamed, "Exact distribution of the Mann-Kendall trend test statistic for persistent data," Journal of Hydrology, vol. 365, no. 1-2, pp. 86-94, 2009.

[27] D. Duhan and A. Pandey, "Statistical analysis of long term spatial and temporal trends of precipitation during 1901-2002 at Madhya Pradesh, India," Atmospheric Research, vol. 122, pp. 136-149, 2013. 


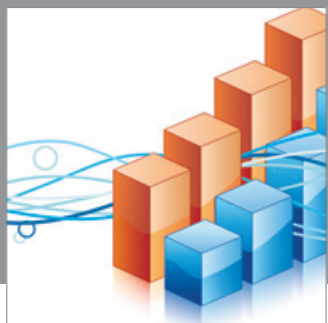

Advances in

Operations Research

mansans

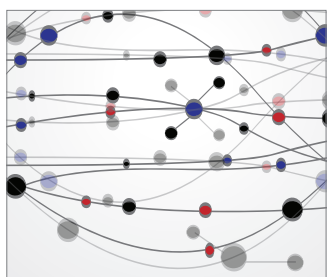

The Scientific World Journal
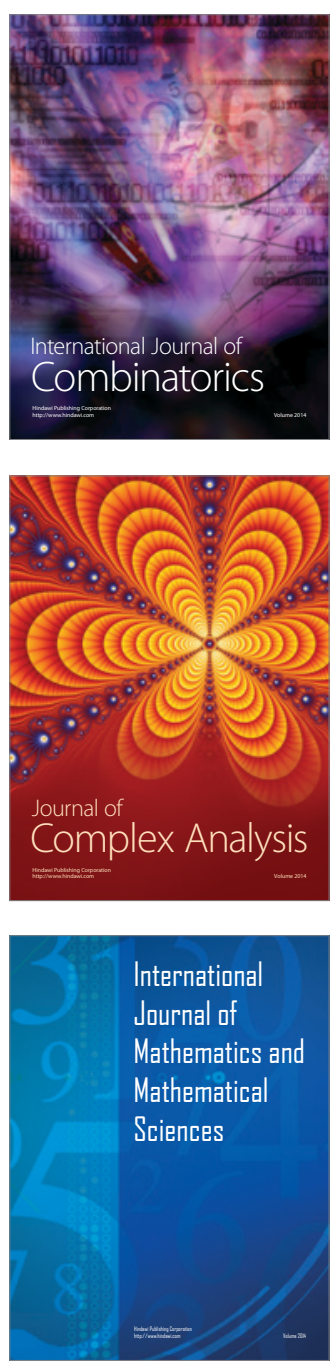
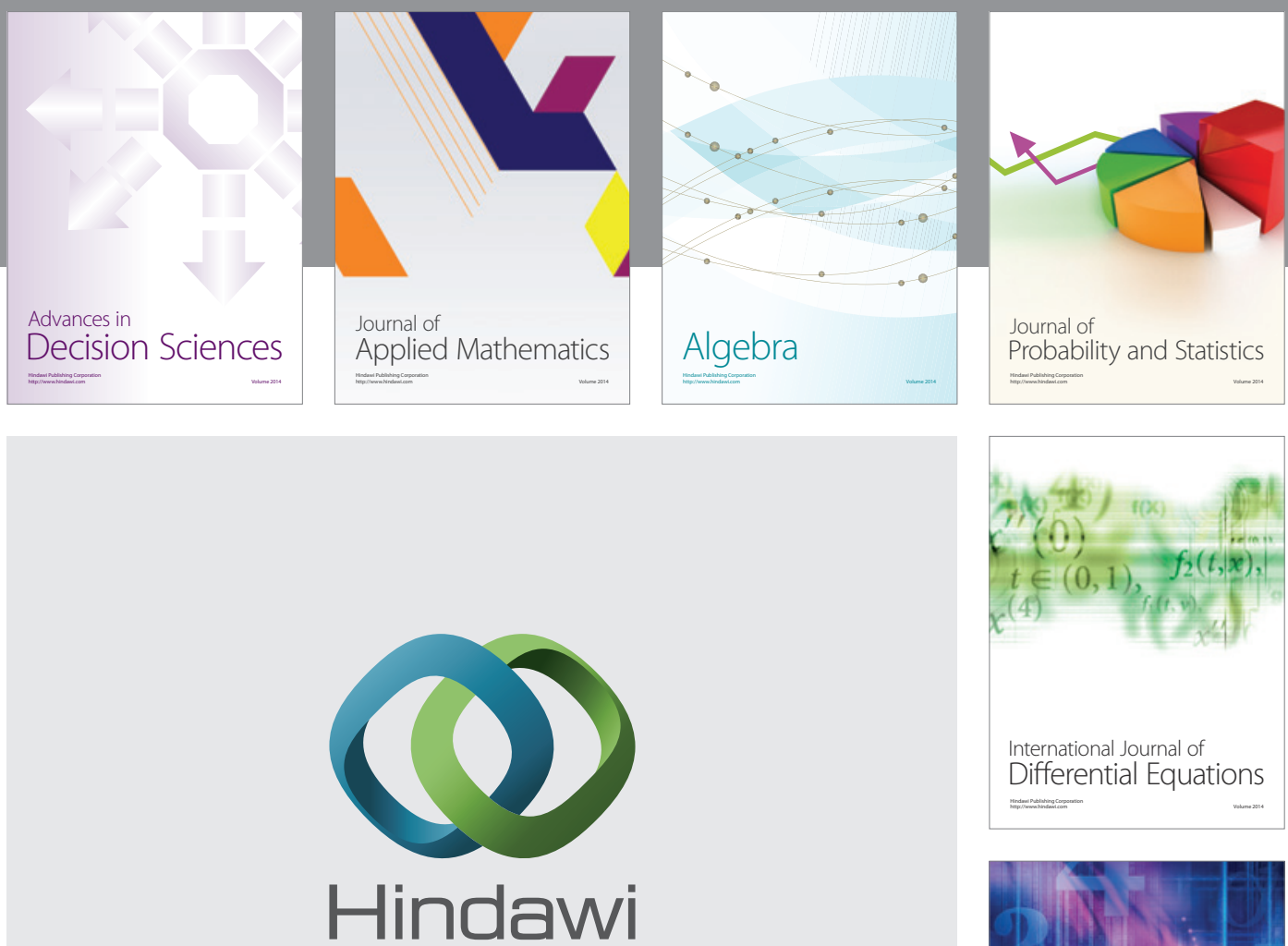

Submit your manuscripts at http://www.hindawi.com
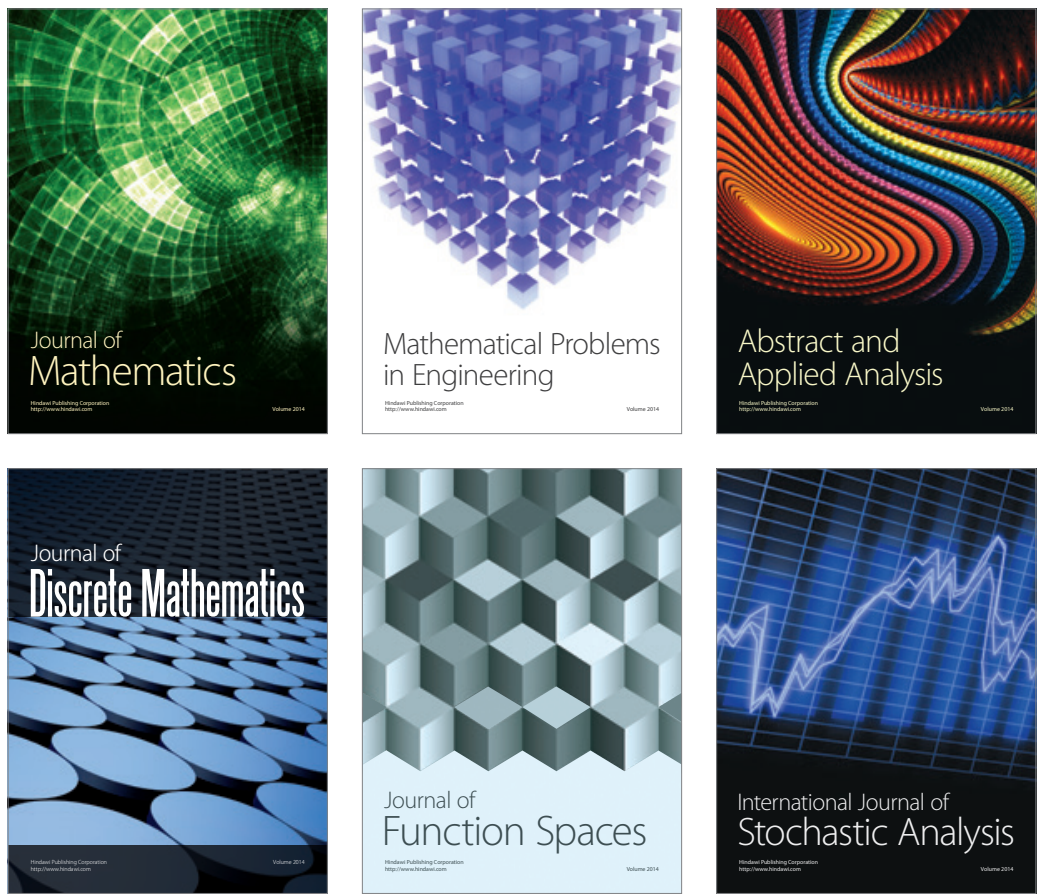

Journal of

Function Spaces

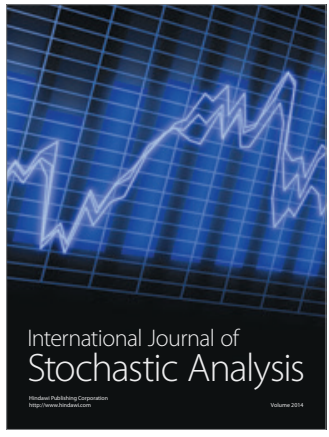

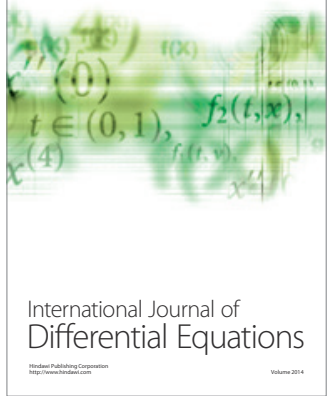
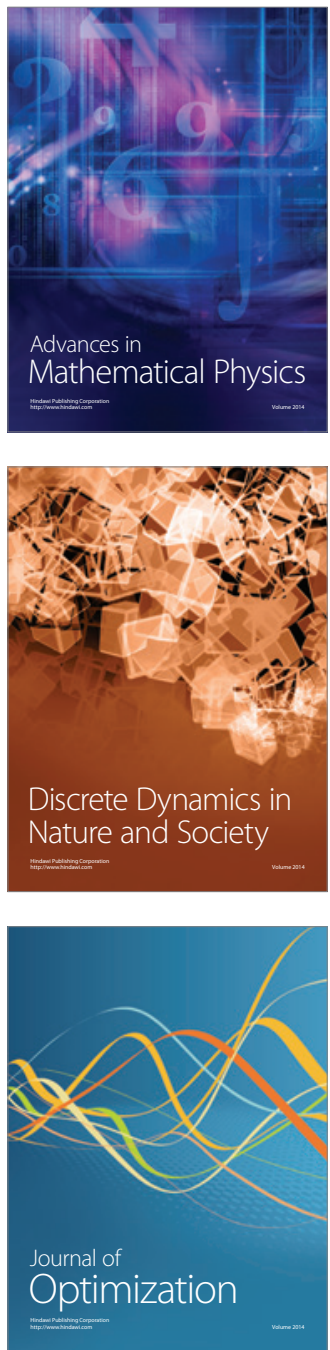